were available and had to cover a wide range of possible microorganisms, whereas other antibiotics were usually used only if sensitivity tests indicated they were appropriate. Therefore the fact that the mortality with kanamycin was the same as with other antibiotics suggests that the broad cover it affords in vitro is matched by efficacy in the Jatient, especially in Gramnegative infections. Once the results of blood cultures and sensitivity tests are at hand a charge of antibiotics is necessary in only a small percentage of infections, including those due to Ps. aeruginosa, which is probably best treated with carbenicillin (Jones and Lowbury, 1967 ; Knudsen et al., 1967 ; Stratford, 1968), and those due to Gram-positive cocci other than staphylococci. Of these, pneumococci and beta-haemolytic streptococci require high dosage of penicillin, which should be added to the initial antibiotic therapy whenever an infection due to one of these organisms is suspected. Str. faecalis will usually respond to ampicillin.

The failure to reduce the high mortality in staphylococcal septicaemia probably stems from two factors. Firstly, the diagnosis is often delayed, perhaps because shock is not very common and occurs late. Secondly, there was usually no specific antibiotic therapy against the staphylococcus in the current series until the culture results were known. While kanamycin did provide in-vitro cover against Staph. aureus in $92 \%$ of the present cases, it may not be as effective in viro, and since May 1968 methicillin has been combined with kanamycin for the initial antibiotic therapy of suspected septicaemia pending the results of blood cultures. Recent reports of increasing incidence of methicillin-resistant staphylococci (Benner and Kayser, 1968 ; Rountree and Beard, 1969) suggest that staphylococcal septicemia will continue to present a therapeutic problem.

We are indebted to Dr. P. M. Rountree for her advice and encouragement.

\section{REFERENCES}

Anderson, R. W., James, P. M., Bredenberg, C. E., and Hardaway, R. M. (1967). Annals of Surgery, 165, 341.

Benner, E. J., and Kayser, F. H. (1968). Lancet, 2, 741.
Bennett, I. L., Finland, M., Hamburger, M., Kass, E. H., Lcpper, M. and Waisbren, B. A.' (1963). Journal of the American Medical Association, 183, 462 .

Blair, E., Buxton, R. W., Cowley, R. A., and Mansberger, A. R., jun. (1961). Fournal of the American Medical Association, 178, 916.

Cavanagh, D., and McLeod, A. G. W. (1966). American Fournal of Obstetrics and Gynaecology, 96, 913.

du Toit, H. J., du Plessis, J. M. E., Dommisse, J., Rorke, M. J., Theron, M. S., and de Villiers, V. P. (1966). Lancet, 2, 143.

Gilbert, R. P. (1960). Physiological Reviews, 40, 245.

Gourzis, J. T., Hollenberg, M. W., and Nickerson, M. (1961). Fournal of Experimental Medicine, 114, 593.

Hassall, J. E., and Rountree, P. M. (1959). Lancet, 1, 213.

Hodgin, U. G., and Sanford, J. P. (1965). American fournal of Medicine, 39, 952.

Jones, R. J., and Lowbury, E. J. L. (1967). British Medical fournal, 3,

79.
Kardos, G. G. (1966). New England fournal of Medicine, 274, 868

Knudsen, E. T., Rolinson, G. N., and Sutherland, R. (1967). British Medical fournal, 3, 75.

Lillihei, R. C., Longerbeam, J. K., Bloch, J. H, and Manax, W. G. (1964). Clinical Pharmacology and Therapeutics, 5, 63.

McCabe, W. R., and Jackson, G. G. (1962). Archives of Internal Medicine, $110,856$.

McGowan, G. K., and Walters, G. (1963). British fournal of Surgery, 50, 821 .

McHenry, M. C., Martin, W. J., and Wellman, W. E. (1962). Annals of Internal Medicine, 56, 207.

Maclean, L. D., Duff, J. H., Scott, H. M., and Perctz, D. I. (1965). Surgery, Gynaecology and Obstetrics, 120, 1.

Melby, J. C., and Spink, W. W. (1958). Fournal of Clinical Investigation, 37, 1791 .

Prout, W. G. (1968). Lancet, 1, 1108.

Rountree, P. M., and Beard, M. A. (1969). Medical fournal of Australia. In press.

Siegel, J. H., Greenspan, M., and Del Guercio, L. R. M. (1967), Annals of Surgery, 165, 504 .

Smith, L. L., and Moore, F. D. (1962). New England Fournal of Medicine, 267, 733

Spink, W. W. (1962). Annals of Internal Medicine, 57, 538 .

Spink, W. W. and Anderson, D. (1954). Fournal of Clinical Investigation, 33, 540 .

Spink, W. W., and Vick, J. (1961). Circulation Research, 9, 184.

Stratford, B. C. (1968). Medical Fournal of Australia, 2, 890 .

Thomas, L. (1956). Fournal of Experimental Medicine, 104, 865.

Udhoji, V. N., and Weil, M. H. (1965). Annals of Internal Medicine, 62, 966.

Waisbren, B. A. (1964). American fournal of Medicine, 36, 819.

Weil, M. H. (1962). Circulation, 5, 718.

Weil, M. H., and Miller, B. S. (1961). Fournal of Laboratory and Clinical Medicine, 57, 683.

Weil, M. H., Shubin, H., and Biddle, M. (1964). Annals of Internal Medicine, 60, 384.

Zweifach, B. W., Nagler, A. L., and Thomas, L. (1956). Fournal of Experimental Medicine, 104, 881.

\title{
Diurnal Variation of Oral Glucose Tolerance : a Possible Pointer to the Evolution of Diabetes Mellitus
}

\author{
R. J. JARRETT,* M.D. ; H. KEEN, $\dagger$ M.B., B.S., M.R.C.P.
}

\begin{abstract}
Cummary : Possible diurnal variation in the blood sugar $\checkmark$ response to oral glucose was studied by comparing, in the same individuals, the results of oral glucose tolerance tests performed in the morning and the afternoon. In a group of normal individuals the blood sugar levels were significantly higher in the afternoon. In hyperglycaemic individuals the diurnal variation decreased as the blood sugar levels reached during the morning test increased, so that in a group of grossly hyperglycaemic men the mean morning and afternoon tests were almost identical. The causes of this diurnal variation are not known.
\end{abstract}

* Lecturer, Department of Medicine, Guy's Hospital, London S.E.1. † Reader in Medicine, Guy's Hospital, London S.E.1.

\section{Introduction}

The traditional oral glucose tolerance test performed after an overnight fast is not very reproducible (McDonald et al., 1965). Some of the factors responsible for variation within individuals are known to include the level of the previous carbohydrate intake, the rate of gastric emptying, perhaps the emotional state, and, in women, the stage of the menstrual cycle. One other factor which might affect glucose tolerance-namely, the time of day at which the test is made-has received little attention. Its immediate practical importance lies particularly in the field of population surveys, for it is obviously more convenient to perform screening tests throughout the working day than to restrict them to the early morning.

In the Tecumseh population survey (Hayner et al., 1965) 
possible diurnal variation in the blood sugar level measured one hour after an oral glucose load was studied in retrospect, and the conclusion reached was that there was no significant effect of time of day. However, inspection of the published data suggests that the opposite conclusion is equally tenable. Bowen and Reeves (1967) performed morning and afternoon tests in a small group of normal individuals and found considerable differences between the responses, the blood sugar levels reaching much higher levels in the afternoon. Furthermore, Roberts (1964) has drawn attention to loss of glucose tolerance in the afternoon and claims this as the earliest evidence of diabetes.

We have investigated possible diurnal variation in three groups of people ; in normals, in subjects with borderline hyperglycaemic abnormalities of glucose tolerance, and in newly detected, grossly hyperglycaemic individuals.

\section{Methods}

At each of the glucose tolerance tests $0 \cdot 1-\mathrm{ml}$. capillary blood samples from ear lobe puncture were obtained in the fasting state and at half-hourly intervals for two hours after drinking $50 \mathrm{~g}$. of liquid glucose (contained in $235 \mathrm{ml}$. of Lucozade). The blood was diluted in $3 \mathrm{ml}$. of $1 \%$ potassium fluoride and the blood sugar estimated by the micro-modification of the ferricyanide reduction method on an AutoAnalyzer (Whichelow et al., 1967). The previous diet was assessed and the carbohydrate intake supplemented to á minimum of $150 \mathrm{~g}$./day before the tests when necessary. The tests were performed in randomized order in respect of time of day.

The following three groups of people were investigated.

\section{(1) Normal Group}

This group consisted of 16 individuals, nine men and seven women, working in the department of medicine at Guy's Hospital. The age range was from 19 to 41 years (mean 27.7 years). The morning test was begun at about 9.30 a.m., after prohibiting food consumption from the preceding midnight. The afternoon test was begun usually between 1 and 2 p.m., five to six hours after completing a light breakfast. The interval between tests was never longer than four days.

\section{(2) Group With " Borderline" Hyperglycaemia}

Bedford Group.-From the people currently attending the Bedford Borderline Diabetic Clinic (Keen et al., 1968), the records of those individuals receiving neither hypoglycaemic drug therapy nor dietary restriction were examined. Five men and five women who had fairly consistently shown blood sugar levels of $120 \mathrm{mg} . / 100 \mathrm{ml}$. or more when measured two hours after oral glucose, and who were not obviously precluded by age or infirmity from attending the clinic, were selected for the present study. Each of them had two morning and two afternoon tests completed over a period of three to four weeks. The morning tests were arranged as for the normal group, but the afternoon tests were begun between 4 and 4.30 p.m., so that the period of fasting was from seven to eight hours. The age range was from 42 to 70 years (mean 56.7 years).

London Group.-This group was derived from a current survey in London of male civil servants aged 40 or more. Among the measurements made at the initial survey examination (which is conducted in the mornings only) was the capillary blood sugar two hours after $50 \mathrm{~g}$. of liquid glucose. This screening level was between 110 and $199 \mathrm{mg}$. $/ 100 \mathrm{ml}$. in 28 men, and they were recalled for two confirmatory glucose tolerance tests, one in the morning and one in the afternoon. They ranged in age from 41 to 73 years, with a mean of 54.5 years. As we had no previous knowledge of their dietary habits they were all asked to supplement their carbohydrate intake to about a minimum of $150 \mathrm{~g}$./day for three days before the tests, which were performed, not more than five days apart, as in the other two groups in the mornings and as in the Bedford group in the afternoons.

\section{(3) Grossly Hyperglycaetnic Group}

Six of the civil servants had screening two-hour blood sugars of $200 \mathrm{mg} . / 100 \mathrm{ml}$. or more. They were recalled and tested in the same way as the London Borderline group. The age range for these individuals was 54 to 64 years, with a mean of $58 \cdot 8$ years.

\section{Results}

Fig. 1 compares the mean blood sugar curves in morning and afternoon tests performed in the normal group and the Bedford Borderline group. Differences in mean blood sugar levels at each time point are shown, together with their statistical significance. In the normal group the afternoon values are higher throughout the test, significantly $(P<0.05)$ at all time points except fasting. In the Borderline group the mean fasting level is significantly lower than the morning one. The mean afternoon "curve" crosses the morning one between 30 and 60 minutes and thereafter is higher than the morning curve, significantly $(P<0.05)$ at 90 and 120 minutes.

In the Bedford Borderline group when the sexes are analysed separately (see Table) the diurnal swing is seen to be greater among the women. A similar sex difference, though of much

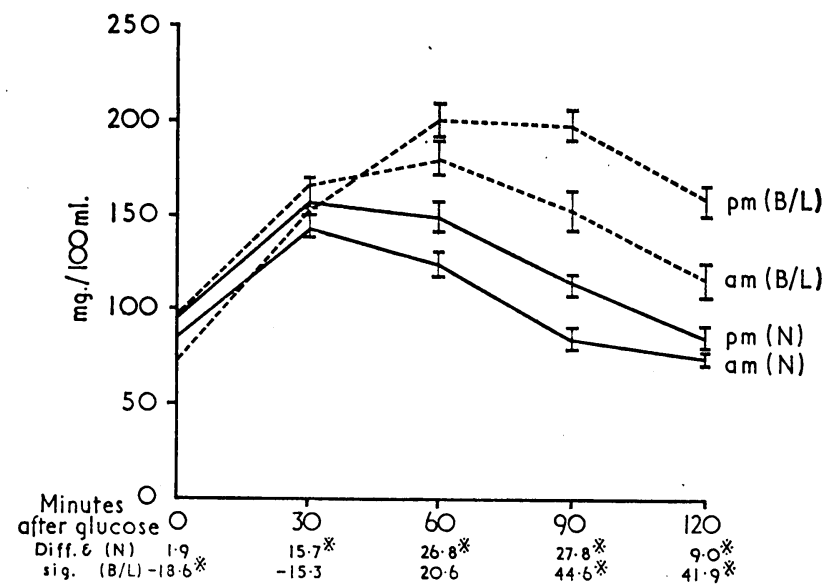

Fig. 1.-Mean ( \pm S.E.M.) blood sugar levels in morning and afternoon glucose tolerance tests in the normal (N) (16 tests) and Bedford Borderline (B/L) (20 tests) groups. The difference between morning and afternoon values is shown below the abscissa. * Indicates that the differences are significant $(P<0.05)$.

Mean Blood Sugar Values at the Five Time Points of the Glucose Tolerance Test for Men and Women Separately. Difference $(\triangle)$ in Mean Values Between Morning and Afternoon Tests are Also Shown

\begin{tabular}{|c|c|c|c|c|c|c|}
\hline \multirow{2}{*}{$\begin{array}{c}\text { Time } \\
\text { (minutes) }\end{array}$} & \multicolumn{3}{|c|}{ Men } & \multicolumn{3}{|c|}{ Women } \\
\hline & a.m. & p.m. & $\Delta$ & a.m. & p.m. & $\Delta$ \\
\hline \multicolumn{7}{|c|}{ Bedford Borderline Group } \\
\hline $\begin{array}{r}0 \\
30 \\
60 \\
90 \\
120\end{array}$ & $\begin{array}{r}99 \cdot 4 \\
164.9 \\
187.7 \\
164 \cdot 1 \\
127.5\end{array}$ & $\begin{array}{r}77 \cdot 4 \\
142 \cdot 7 \\
191 \cdot 3 \\
194 \cdot 2 \\
155 \cdot 7\end{array}$ & $\begin{array}{r}22 \cdot 0 \\
22 \cdot 2 \\
3 \cdot 6 \\
30 \cdot 1 \\
28 \cdot 2\end{array}$ & $\begin{array}{r}89.1 \\
157.9 \\
174.4 \\
144.9 \\
106.0\end{array}$ & $\begin{array}{r}74.0 \\
148.5 \\
212.0 \\
204.0 \\
161.5\end{array}$ & $\begin{array}{r}15 \cdot 1 \\
9.4 \\
37.6 \\
59.1 \\
55.5\end{array}$ \\
\hline \multicolumn{7}{|c|}{ Normal Group } \\
\hline $\begin{array}{r}0 \\
30 \\
60 \\
90 \\
120\end{array}$ & $\begin{array}{r}84.9 \\
147.0 \\
125.7 \\
81.0 \\
67.2\end{array}$ & $\begin{array}{r}89 \cdot 7 \\
162 \cdot 8 \\
146 \cdot 7 \\
104 \cdot 8 \\
80 \cdot 7\end{array}$ & $\begin{array}{r}4 \cdot 8 \\
15 \cdot 8 \\
21 \cdot 0 \\
23 \cdot 8 \\
13 \cdot 5\end{array}$ & $\begin{array}{r}85 \cdot 1 \\
136 \cdot 1 \\
120 \cdot 4 \\
91 \cdot 0 \\
77 \cdot 3\end{array}$ & $\begin{array}{r}83.3 \\
152.1 \\
154.9 \\
123.9 \\
88.7\end{array}$ & $\begin{array}{r}1.8 \\
16.0 \\
34.5 \\
32.9 \\
11.4\end{array}$ \\
\hline
\end{tabular}


less magnitude, occurred in the normal group. As the numbers are small this apparent sex difference is difficult to evaluate. However, it is worth noting that Bowen and Reeves (1967) found larger diurnal swings than ours in their normal group, which was composed predominantly of women.

Our results for the London civil servants have been analysed in three subgroups: (1) those with screening blood sugar values of $110-120 \mathrm{mg} . / 100 \mathrm{ml}$. ("low" screeners), (2) those with screening values from 121 to $199 \mathrm{mg} . / 100 \mathrm{ml}$. (" high" screeners), and (3) those screening at $200 \mathrm{mg} . / 100 \mathrm{ml}$. and above. The mean curves for these groups are shown in Figs. 2 and 3. Those screening "low" resemble both the normal and the Bedford Borderline groups in showing distinct differences between the morning and the afternoon test. Those screening "high" have both an abnormal morning and afternoon test, with little difference between them, thus resembling the "diabetic" group (Fig. 3).

Fig. 4 shows the degree of variation between morning and afternoon tests in two selected individuals. One has a normal test in the morning and a "borderline diabetic" result in the afternoon; the other, on whom paired tests were performed, has a normal mean morning test but a frankly diabetic response in the afternoon.

\section{Discussion}

The data presented above clearly show the phenomenon of diurnal variation in the response to oral glucose. The variation which exists in normal.people may be exaggerated with slight degrees of glucose intolerance, but appears to be lost in the diabetic. Variation may be greater in women than in men, but further comparisons are necessary to confirm this. It is also possible for some individuals to have normal oral glucose tolerance in the morning and abnormal tolerance in the afternoon. This observation is of considerable importance, not only to those interested in diabetes prevalence but also to those involved in studies on the aetiology of diabetes. For several years there has been considerable debate concerning the presence of vascular changes in prospective diabetics before the appearance of abnormal glucose tolerance, culminating in the report (Siperstein et al., 1966) of muscle capillary basement membrane thickening in close relatives of diabetics. The mean oral glucose tolerance of these relatives was similar to that of a control group, and the conclusion to be drawn is that the basement membrane thickening is the result of some undefined "diabetic" process which precedes or may be responsible for the hyperglycaemia. However, it is now arguable that evaluation of glucose tolerance should include the more provocative afternoon test, for apparently normal individuals may spend much of the day in a state of relative hyperglycaemia.

The available information concerning diurnal variation in glucose tolerance, though incomplete, does suggest a working hypothesis concerning the evolution of diabetes of the " maturity onset" variety. Thus normal individuals may show a small diurnal swing in their response to oral glucose. With some loss of homoeostatic control, first the afternoon test becomes abnormal, as in our Bedford group, a phenomenon which may be comparable to the response to the provocative cortisone glucose tolerance test. Later the morning test also becomes abnormal, leading to eventual loss of the diurnal variation, as seen in the men with the high morning screening blood sugar values.

What mechanism or mechanisms underlie the diurnal rhythm? It cannot be attributed to the diurnal adrenocorticoid rhythm, for plasma cortisol levels are higher in the morning than in the afternoon (Doe et al., 1956). There is some evidence to suggest that it may be due to diurnal variation in the sensitivity of the pancreatic B cells to insulinotropic stimuli. Thus Freinkel et al. (1968) subjected 11 young men to total fasting for three to four days. At similar blood glucose levels the morning plasma insulin level was twice that in the afternoon, suggesting that there is an inherent rhythm in the release of insulin from the pancreas. Malherbe et al. (1968) studied the influence of the time of day on the blood sugar and plasma insulin responses to three isocaloric meals. In the morning the insulin response was brisk and high, at midday it was low, and in the evening it was intermediate and prolonged. Similar results have been reported by Rigas et al. (1968). It is very probable, therefore, that normal diurnal variation in oral glucose tolerance is secondary to diurnal variation in the amount of insulin released by the pancreas in response to a stimulus. From this hypothesis it would be expected that abnormal glucose homoeostasis should coexist with abnormal insulin homoeostasis, an association which has, of course, been frequently documented.

We are grateful to the many individuals who so willingly partipated in our study. The Bedford and London Borderline Diabetes

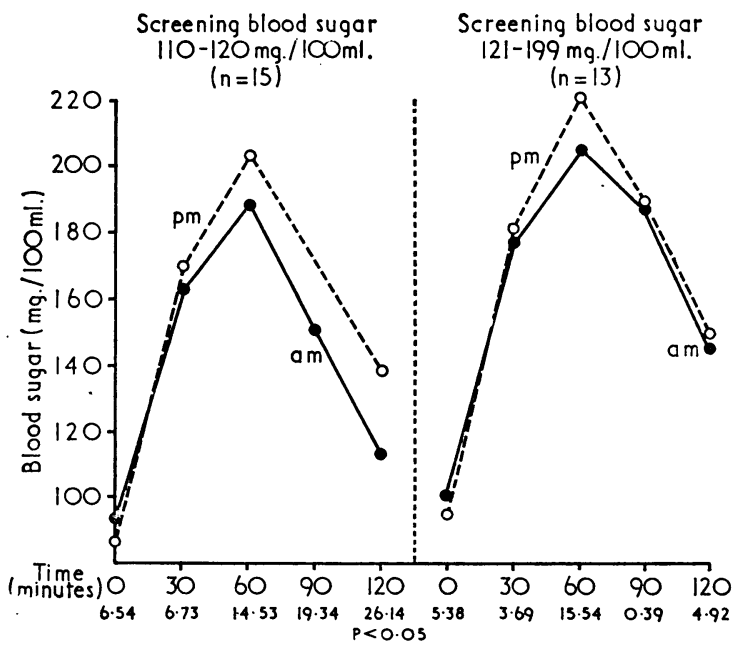

FIG. 2

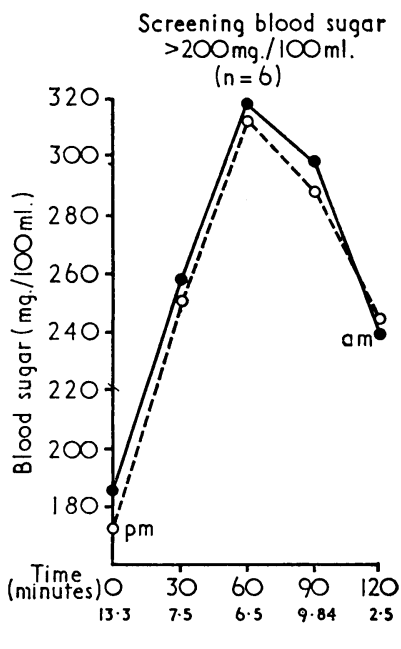

Fig. 3

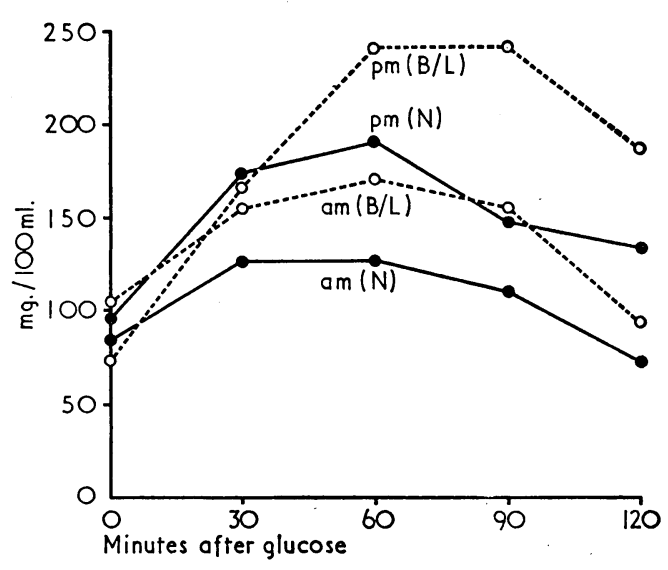

FIG. 4

Fig. 2.- Mean blood sugar levels in morning and afternoon glucose tolerance tests in two groups of men from the London Survey (see text). The difference between morning and afternoon values is shown below the abscissa. FIG. 3. - Mean blood sugar levels in morning and afternoon glucose tolerance tests in the grossly hyperglycaemic group of men from the London survey. The difference between morning and afternoon values is shown below the abscissa. FIG. 4. - Results of single morning and afternoon tests in one individual from the normal group (N) and of paired morning and afternoon tests in one individual from the Bedford Borderline group $(B / L)$. 
Studies were financed by the Ministry of Health, and the present study was also supported by a grant to one of us (R. J. J.) from Lilly Laboratories.

\section{REFERENCES}

Bowen, A. J., and Reeves, R. L. (1967). Archives of Internal Medicine, 119, 261.

Doe, R. P., Flink, E. B., and Goodsell, M. G. (1956). Fournal of Clinical Endocrinology, 16, 196.

Freinkel, N., Mager, M., and Vinnick, L. (1968). Fournal of Laboratory and Clinical Medicine, 71, 171.

Hayner, N. S., Kjelsberg, M. D., Epstein, F. H., and Francis, T., jun. (1965). Diabetes, 14, 413.
Keen, H., Jarrett, R. J., Chlouverakis, C., and Boyns, D. R. (1968). Postgraduate Medical fournal, 44, 960.

McDonald, G. W., Fisher, G. F., and Burnham, C. (1965). Diabetes, 14 473.

Malherbe, C., de Gasparo, M., Heller, F., and Hoet, J. J. (1968). 4th meeting of the European Association for the Study of Diabetes Louvain, 14 July.

Rigas, A. N., Bittles, A. H., Hadden, D. R., and Montgomery, D. A. D. (1968). British Medical fournal, 4, 25.

Roberts, H. J. (1964). Fournal of the American Geriatrics Society, 12, 423.

Siperstein, M. D., Norton, W., Unger, R. H., and Madison, L. L. (1966) Transactions of the Association of American Physicians, 79, 330.

Whichelow, M. J., Wigglesworth, A., Cox, B. D., Butterfield, W. J. H., and Abrams, M. E. (1967). Diabetes, 16, 219.

\title{
Exchangeable Potassium Study in Patients Undergoing Chronic Haemodialysis
}

\author{
Y. K. SEEDAT,* M.D., M.R.C.P., F.C.P.(S.A.)
}

British Medical fournal, 1969, 2, 344-345

Summary : Seven patients with chronic renal failure treated with haemodialysis for 4 to 24 months were found to have low exchangeable potassium levels. Before dialysis the plasma potassium was normal or somewhat raised (possibly owing to acidosis), though the exchangeable potassium was low. Acidosis was corrected during dialysis; plasma potassium levels fell, but clinical and electrocardiographic changes of hypokalaemia were absent. The level of $1 \mathrm{mEq} /$ litre in the dialysate fluid may be too low for use in prolonged haemodialysis.

\section{Introduction}

Haemodialysis is now an established procedure in the treatment of patients with chronic renal failure. The long-term effect of haemodialysis on the electrolyte changes in the patient has not been ascertained. This study was done to determine the exchangeable potassium level of patients undergoing haemodialysis for months.

\section{Material and Methods}

Seven patients undergoing chronic haemodialysis by means of a two-layered Kiil dialyser for periods ranging from 4 to 24 months were selected for this study. Exchangeable potassium levels were determined with radioactive ${ }^{42} \mathrm{~K}$ as described by Veall and Vetter (1958). Veall and Vetter stated: "The exchangeable $\mathrm{K}$ probably represents all the exchangeable potassium in normal subjects and about $90-95 \%$ in those diseased patients where equilibrium is delayed. ... Though an agreement is better if 48 hours are allowed for equilibration, this not only necessitates a fourfold increase in the tracer dose owing to the short radioactive half life, but it also makes multiple tracer studies more complicated."

With this in mind, and because of difficulties in doing a 48-hour exchangeable potassium in patients who were dialysed every second or third day, the isotope was administered orally 24 to 48 hours before dialysis, and the sample for determining specific activity was taken after a 24 -hour period for equilibra-

* University Department of Medicine, the Roypl Infirmary, Manchester 13. At present Senior Physician/S€nior Lecturer, D partment of Medicine, University of Natal, P.O. Box 39, Congella, Durban, South Africa. tion. Estimation of ${ }^{42} \mathrm{~K}$ was carried out in the saliva in patients with anuria. In patients with adequate urine output specific activity of ${ }^{42} \mathrm{~K}$ was estimated in both urine and saliva and there was a close correlation between the two results $(r=0.96$, see Table I). Plasma potassium and $\mathrm{pH}$ of the blood according to the method of Siggard Andersen et al. (1960) were done before and after dialysis. The level of potassium in the dialysate fluid was $1 \mathrm{mEq} /$ litre. The diet of the patients contained $58 \mathrm{mEq}$ of potassium per day and cation-exchange resins were not routinely used. Dialysis in Cases 1-6 were carried out three times a week and in Cases 7 and 8 twice a week. The duration of dialysis per week varied from 14 to 42 hours, and this was determined by the age and size of the patient, the need to obtain adequate control of the blood urea, plasma potassium, haemoglobin, and treatment of any complications such as peripheral neuritis.

\section{Results}

Seven of the patients who were dialysed for a period of at least four months were found to have a low exchangeable potassium level (Table I) ; the normal exchangeable potassium for males is $46 \pm 3.5 \mathrm{mEq} / \mathrm{kg}$. body weight and for females $37.5 \pm 3 \cdot 2 \mathrm{mEq} / \mathrm{kg}$. body weight (de Deuxchaisnes et al., 1961). Five of the seven had an exchangeable potassium deficit of 20 to $35 \%$. The level of the exchangeable potassium was

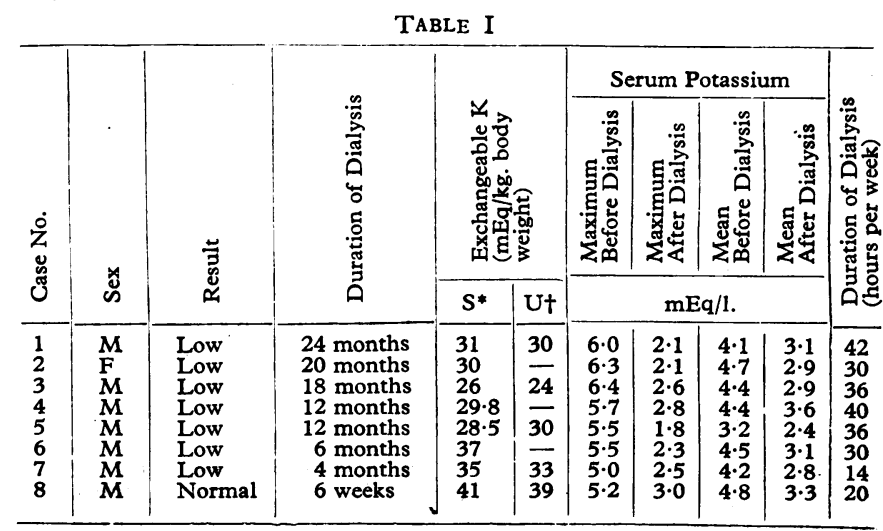
$S=$ Estimation of potassium in saliva
$+U=$ Estimation of potassium in urine. 